(C) 2006 American Thoracic Society

doi: $10.1164 / \mathrm{rccm} .200506-8650 \mathrm{C}$

\title{
Do Inhaled Carbon Nanoparticles Translocate Directly into the Circulation in Humans?
}

\author{
Nicholas L. Mills, Nadia Amin, Simon D. Robinson, Atul Anand, John \\ Davies, Dilip Patel, Jesus M. de la Fuente, Flemming R. Cassee, Nicholas \\ A. Boon, William MacNee, Alistair M. Millar, Ken Donaldson and David E. \\ Newby
}

Centre for Cardiovascular Science; ELEGI Colt Research Laboratories, University of Edinburgh; Department of Radiology; Radiopharmacy, Royal Infirmary of Edinburgh, Edinburgh; Centre for Cell Engineering, Glasgow University, Glasgow, United Kingdom; and National Institute for Public Health and the Environment, Bilthoven, The Netherlands

Correspondence and requests for reprints should be addressed to Nicholas $L$. Mills, M.B.Ch.B., M.R.C.P., Centre for Cardiovascular Science, The University of Edinburgh, Chancellor's Building, Edinburgh EH16 4SB, UK. E-mail:

nick.mills@ed.ac.uk

\begin{abstract}
Rationale: Increased exposure to particulate air pollution $\left(\mathrm{PM}_{10}\right)$ is a risk factor for death and hospitalization with cardiovascular disease. It has been suggested that the nanoparticulate component of $\mathrm{PM}_{10}$ is capable of translocating into the circulation with the potential for direct effects on the vasculature.
\end{abstract}

Objective: The study's aim was to determine the extent to which inhaled technetium-99m ( ${ }^{99 \mathrm{~m}} \mathrm{Tc}$ )-labeled carbon nanoparticles (Technegas) were able to access the systemic circulation.

Methods and Main Results: Ten healthy volunteers inhaled Technegas and blood samples were taken sequentially over the following $6 \mathrm{~h}$. Technegas particles were 4-20 nm in diameter and aggregated to a median particle diameter of approximately $100 \mathrm{~nm}$. Radioactivity was immediately detected in blood, with levels increasing over $60 \mathrm{~min}$. Thin-layer chromatography of whole blood identified a species that moved with the solvent front, corresponding to unbound

${ }^{99 m}$ Tc-pertechnetate, which was excreted in urine. There was no evidence of particle-bound ${ }^{99 \mathrm{~m}} \mathrm{Tc}$ at the origin. ${ }^{7}$ Camera images demonstrated high levels of Technegas retention $(95.6 \pm 1.7 \%$ at $6 \mathrm{~h}$ ) in the lungs, with no accumulation of radioactivity detected over the liver or spleen.

Conclusions: The majority of ${ }^{99 \mathrm{~m}} \mathrm{Tc}$-labeled carbon nanoparticles remain within the lung up to $6 \mathrm{~h}$ after inhalation. In contrast to previous published studies, thinlayer chromatography did not support the hypothesis that inhaled Technegas carbon nanoparticles pass directly from the lungs into the systemic circulation. 
Epidemiologic studies have demonstrated that exposure to air pollution is an important risk factor in the development of cardiovascular disease (1-3). The World Health Organization identifies particulate matter with an aerodynamic diameter of less than $10 \mu \mathrm{m}\left(\mathrm{PM}_{10}\right)$ as the most hazardous component of air pollution. However, only fine particles with a diameter less than $2.5 \mu \mathrm{m}\left(\mathrm{PM}_{2.5}\right)$ are able to penetrate to the terminal bronchioles and proximal alveoli to any great extent. Nanoparticles have a diameter of less than $0.1 \mu \mathrm{m}$, and while constituting a small fraction of the total mass of ambient particulate matter, they represent a substantial proportion in terms of particle number. Toxicologists suggest that the nanoparticulate component of ambient particulate matter is the most potent and likely to be responsible for adverse cardiovascular health effects (4).

The precise mechanism by which air pollution influences cardiovascular risk has not been determined. However, a number of interesting hypotheses have been proposed to explain how inhaled particles could interact with the cardiovascular system $(1,5)$. The traditional view is that inhaled particles provoke an inflammatory response in the lungs, with consequent release of prothrombotic and inflammatory cytokines into the circulation (6). However, a recent publication by Nemmar and colleagues suggests that inhaled insoluble nanoparticles may be capable of rapid translocation into the circulation (7), with the potential for direct effects on hemostasis or cardiovascular integrity. They used an aerosol of technetium-99m ( ${ }^{99 m} \mathrm{Tc}$ )-labeled carbon nanoparticles, Technegas (Vita Medical Ltd., Sydney, Australia), which is used routinely in clinical practice for radionuclide lung ventilation imaging. Primary Technegas particles are 7 to $23 \mathrm{~nm}$ in diameter and aggregate to a mean particle diameter of approximately $100 \mathrm{~nm}$ (8). Thinlayer chromatography of whole blood identified the presence of ${ }^{99 \mathrm{~m}} \mathrm{Tc}$-labeled carbon nanoparticles in the bloodstream as early as 1 min after Technegas inhalation.

Although a number of relevant studies have been conducted in animals $(9,10)$, the work by Nemmar and colleagues is the only study to date that suggests translocation of insoluble inhaled nanoparticulate to the circulation in humans. Alternative explanations for Nemmar and colleagues' findings have been proposed, which focus on the method of Technegas generation $(11,12)$. In particular, the rapid clearance of ${ }^{99 \mathrm{~m}} \mathrm{Tc}$ from the lungs in this study suggests the presence of large quantities of soluble unbound ${ }^{99 \mathrm{~m}} \mathrm{Tc}$ in both the aerosol and bloodstream. The original study did not report the proportion of ${ }^{99 \mathrm{~m}} \mathrm{Tc}$ remaining in the lung, preventing comment on the importance of this clearance mechanism. As part of a study into the vascular effects of combustion-derived nanoparticulate, we reinvestigate whether inhaled Technegas nanoparticles enter the circulation in humans. Some of the results of this study have been previously reported in the form of an abstract (13).

\section{METHODS}

Ten healthy nonsmoking volunteers (five male, five female; aged 21- $24 \mathrm{yr}$ ) participated in the study, which was undertaken with the approval of the local research ethics committee, in accordance with the Declaration of Helsinki, and with the written, informed consent of each subject. Volunteers were lifelong nonsmokers with normal lung function and no regular exposure to dust or passive smoke in the workplace. None of the volunteers had infective illnesses or received medication other than oral contraception in the week before the study.

Immediately after aerosol generation, subjects inhaled approximately $100 \mathrm{MBq}$ of Technegas in three breaths via a mouthpiece according to standard clinical procedure (14). Subjects rinsed their mouths with water after inhalation to 
minimize delivery to the gastrointestinal tract. Blood samples for thin-layer chromatography and measurement of activity were collected via a 17-gauge intravenous cannula into 2.9-ml citrated blood tubes (Sarstedt-Monovette, Nümbrecht, Germany) at 1, 10, 30,60, and 360 min after Technegas inhalation. A urine sample was collected $60 \mathrm{~min}$ after inhalation. The activity of each sample was measured with a $\gamma$ counter (Cobra II Auto-Gamma; Packard Bioscience Co., Frankfurt, Germany), decay corrected to the time of Technegas inhalation, and expressed as counts per minute per gram of whole blood or urine.

\section{Technegas Generation}

Technegas was generated using a commercially available generator (Technegas generator; Vita Medical Ltd., Sydney, Australia) and following the manufacturer's recommended protocol (15). Briefly, $0.14 \mathrm{ml}$ of sodium ${ }^{99 \mathrm{~m}} \mathrm{Tc}$-pertechnetate $\left(\mathrm{Na}^{99 \mathrm{~m}} \mathrm{TcO}_{4}\right)$ solution $(2 \mathrm{GBq} / \mathrm{ml})$ was added to a graphite crucible. The solution was evaporated to dryness during the 10-min simmer phase. The Technegas was then generated during the burn phase in which the crucible was resistively heated at $2,550^{\circ} \mathrm{C}$ for $15 \mathrm{~s}$ in an atmosphere of $99.998 \%$ argon.

To obtain samples for in vitro studies, Technegas was drawn through $10 \mathrm{ml}$ of liquid in a conical flask; distilled water was used for electron microscopy and $0.9 \%$ sodium chloride in water for thin-layer chromatography.

\section{Particle Sizing}

Samples for particle sizing by transmission electron microscopy were prepared by placing one drop of the Technegas suspension on a copper grid coated with a carbon film. The grid was left to dry in air at room temperature. Particles were sized using a transmission electron microscope (JEM-1200EX; JEOL, [UK] Ltd., Herts, UK) working at $80 \mathrm{kV}$. Particle size distribution was evaluated using an automatic image analyzer and Origin software (OriginLab Corp., Northampton, MA). The size distribution of aggregates in the aerosol was measured at the outlet of the Technegas generator by a scanning mobility particle sizer (TSI, Inc., Shoreview, MN), which consists of a condensation particle counter and a differential mobility analyzer, and can detect aerosol particles in the size range from 7 to $487 \mathrm{~nm}$.

\section{Thin-Layer Chromatography}

Thin-layer chromatography was performed on $20-\times 2.5-\mathrm{cm}$ silica gelimpregnated glass fiber plates (Pall Corporation, New York, NY) with a mobile phase of $0.9 \%$ sodium chloride in water. A $50-\mu$ l blood sample was applied $2.5 \mathrm{~cm}$ from the bottom of the plate. The plate was placed immediately in the mobile phase and the solvent front was allowed to rise $12 \mathrm{~cm}$. The plate was cut into 1$\mathrm{cm}$-high transverse strips starting $0.5 \mathrm{~cm}$ below the origin. This resulted in 13 strips. These were placed into tubes in pairs with only a single strip in the final tube. The count rate from each tube was measured using an automatic 7 counter (Cobra II Auto-Gamma; Packard Bioscience Co.). Each strip was counted for 10 min. The chromatogram was constructed by expressing the count rate from each tube as a percentage of the total of the count rates from all seven tubes. A blood sample from one subject was analyzed in triplicate to assess repeatability of the thin-layer chromatographic technique.

Control samples consisting of Technegas in $0.9 \%$ sodium chloride solution, sodium ${ }^{99 m}$ Tc-pertechnetate solution, whole blood + Technegas solution, and whole blood + sodium ${ }^{99 \mathrm{~m}}$ Tc-pertechnetate solution were prepared and analyzed by thin-layer chromatography. The potential for dissociation of the particle-bound ${ }^{99 \mathrm{~m}} \mathrm{Tc}$ in Technegas to unbound ${ }^{99 \mathrm{~m}} \mathrm{Tc}$-pertechnetate in vitro was assessed by thin- 
layer chromatography of the Technegas sample in $0.9 \%$ sodium chloride solution at 1,60 , and $360 \mathrm{~min}$ after aerosol generation.

\section{Radionuclide Imaging}

Between 0 and 5 min after inhalation of the Technegas, a static image of the thorax was acquired with a GE Millennium 7camera (General Electric, Giles, UK). This was followed by the acquisition of 10 dynamic abdominal images between 5 and 55 min. Further 5-min static thoracic and abdominal images were acquired at 60 and 360 min to assess pulmonary retention of ${ }^{99 \mathrm{~m}} \mathrm{Tc}$.

\section{Data Analysis}

All results included a correction for background radioactivity and the decay of ${ }^{99 \mathrm{~m}} \mathrm{Tc}$ (half-life $=6.02 \mathrm{~h}$ ), with values presented as mean \pm SEM. The total amount of radioactivity in the lung was recorded as total counts from each 5-min static image taken at 0,60, and $360 \mathrm{~min}$. The bladder and left and right upper quadrants of the abdomen were selected as regions of interest on the dynamic scans. Radioactivity within each region of interest was recorded as counts per pixel from each 5-min abdominal image and expressed as a percentage of initial lung radioactivity.

\section{RESULTS}

A size distribution study of Technegas particles $(n=1,500)$ using transmission electron microscopy indicated that the majority of particles were 4 to $20 \mathrm{~nm}$ in diameter (Figure 1). There appeared to be a bimodal distribution, where more than two-thirds of all particles were less than $10 \mathrm{~nm}$ in diameter with a mode of 4 $\mathrm{nm}$, one-third were larger with a mode of $15 \mathrm{~nm}$, and rare aggregates were seen of up to $200 \mathrm{~nm}$. Inhaled particles also had a bimodal distribution with the first peak, due to primary particles, increasing exponentially to the lower detection limit of the scanning mobility particle sizer at $7 \mathrm{~nm}$. The size of aggregated particles showed a log-normal distribution and typically ranged from 50 to 150 $\mathrm{nm}$, with a count median diameter of $108 \mathrm{~nm}$ (geometric SD $=2.2 \mathrm{~nm}$ ).

A

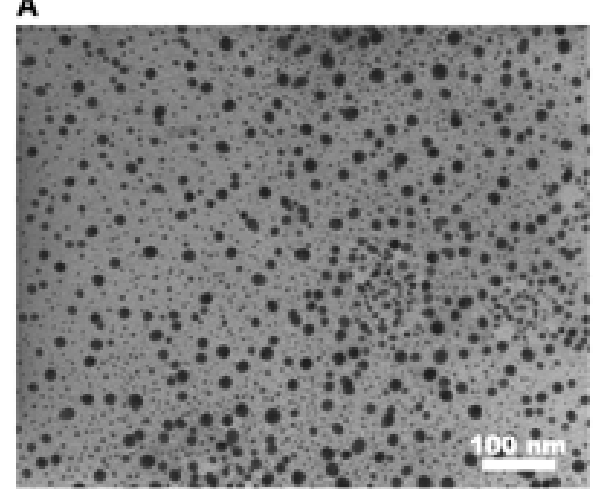

B

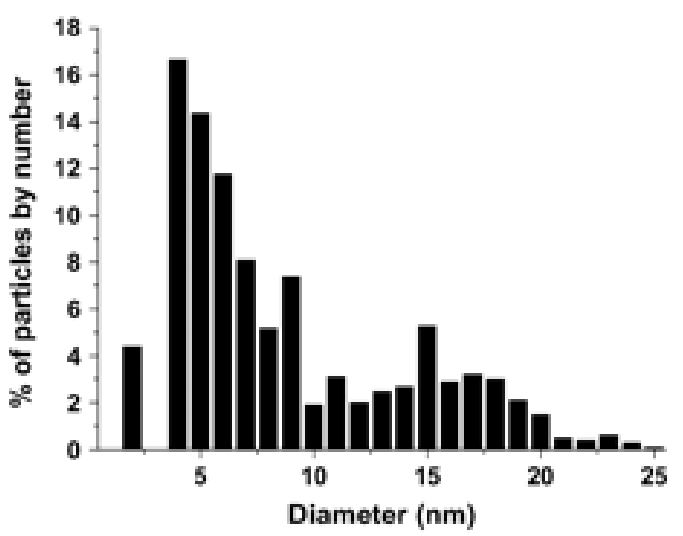

Figure 1. (A) Transmission electron micrograph of Technegas particles and $(B)$ a size distribution study of 1,500 Technegas particles

Radioactivity was detected in whole blood within the first minute, reaching a maximum at $60 \mathrm{~min}$, and declining thereafter (Figure 2). 


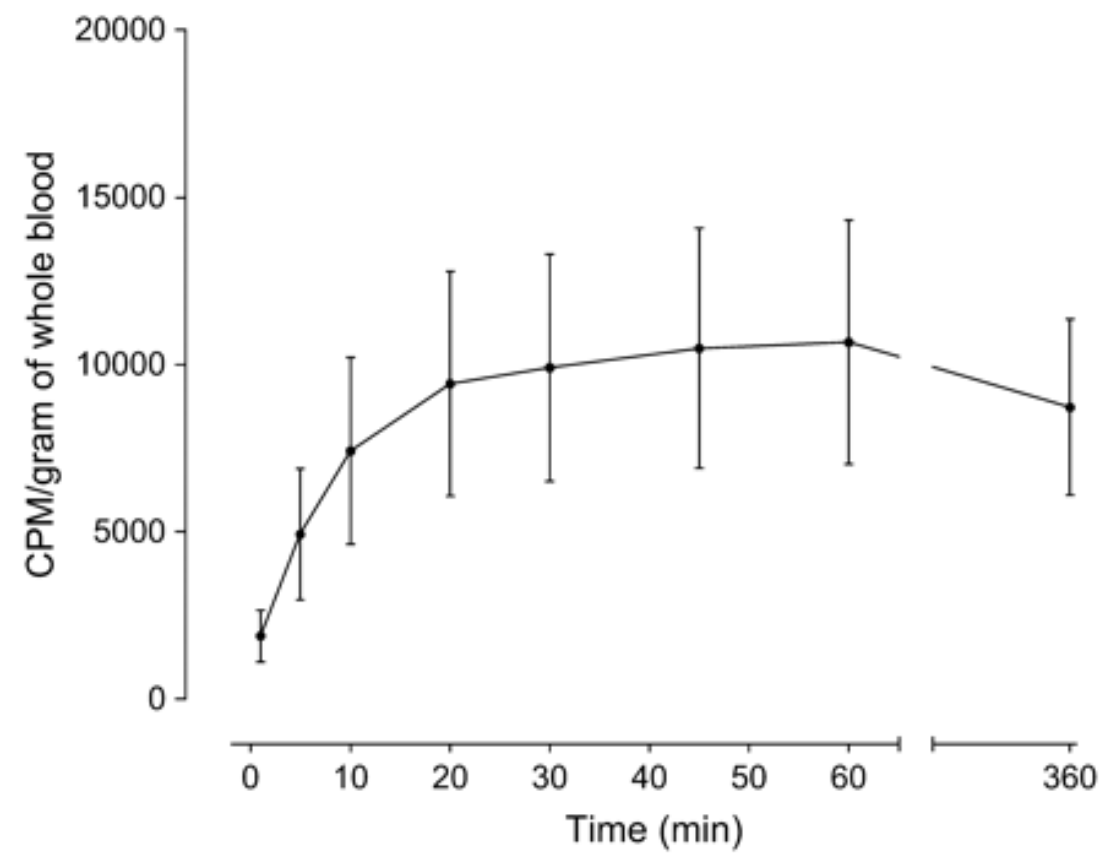

Figure 2. Radioactivity measured as counts per minute (CPM) per gram of whole blood at intervals after inhalation of Technegas. Values are mean \pm SEM.

Thin-Layer Chromatography

In the chromatograms obtained from blood samples taken at 1, 10, 30, and 60 min after Technegas inhalation, there was little evidence of ${ }^{99 \mathrm{~m}} \mathrm{Tc}$ at the origin, but a consistent peak trailing the solvent front was seen at all time points (Figure 3 ). The large error bar at the origin, seen at $1 \mathrm{~min}$, was due to a single outlier. A small peak was present at the origin at $360 \mathrm{~min}$.
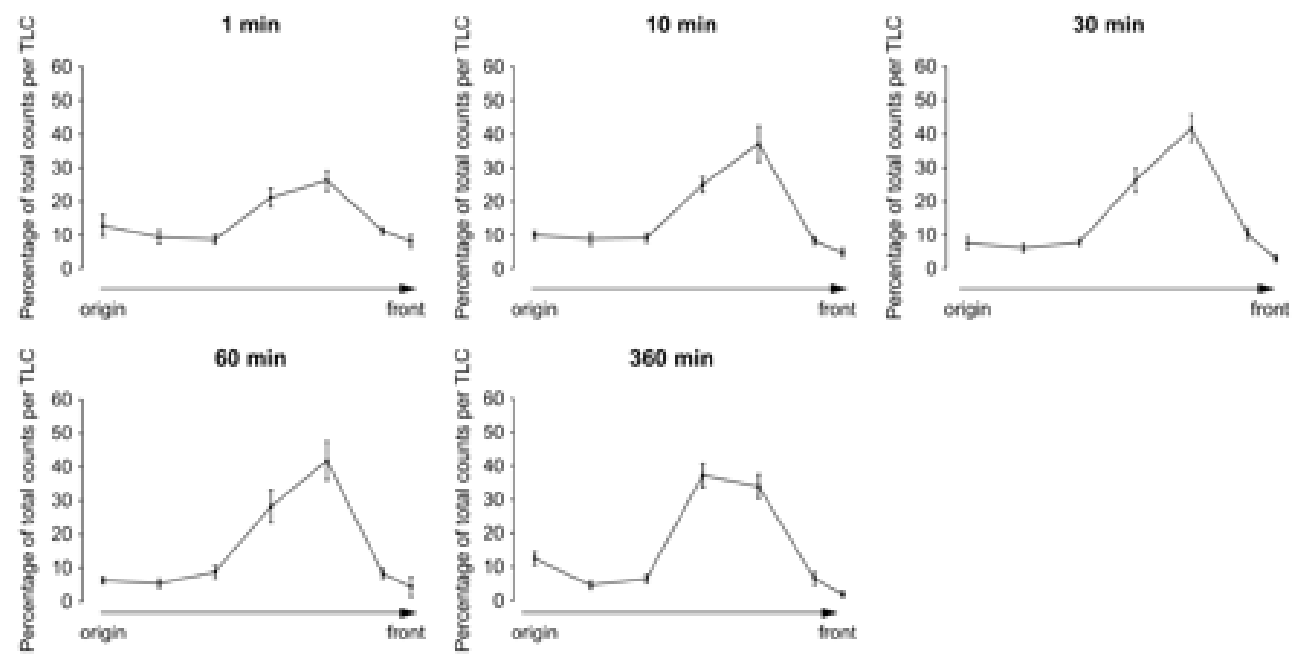

Figure 3. Thin-layer chromatograms from whole blood samples taken 1, 10, 30, 60 , and $360 \mathrm{~min}$ after inhalation of Technegas. TLC = thin-layer chromatography. Values are mean \pm SEM 
Chromatography of sodium ${ }^{99 \mathrm{~m}}$ Tc-pertechnetate solution resulted in a single peak at the solvent front (Figure 4A). Chromatography of Technegas aerosol solution (Figure 4B) resulted in two peaks, one at the origin and one at the solvent front. This is consistent with the presence of both particle-bound ${ }^{99 \mathrm{~m}} \mathrm{Tc}$ and unbound ${ }^{99 \mathrm{~m}} \mathrm{Tc}$-pertechnetate. The ratio of particle-bound ${ }^{99 \mathrm{~m}} \mathrm{Tc}$ to unbound ${ }^{99 \mathrm{~m}} \mathrm{Tc}$ pertechnetate did not change over 360 min, suggesting that the Technegas aerosol contained both particle-bound and unbound ${ }^{99 \mathrm{~m}} \mathrm{Tc}$ at the onset, and that dissociation of ${ }^{99 \mathrm{~m}} \mathrm{Tc}$ from the particles does not occur in vitro. A single peak was seen at the solvent front in urine sampled 60 min after Technegas inhalation (Figure $4 \mathrm{C}$ ), suggesting that unbound ${ }^{99 \mathrm{~m}} \mathrm{Tc}$-pertechnetate or a similar species is excreted in the urine.
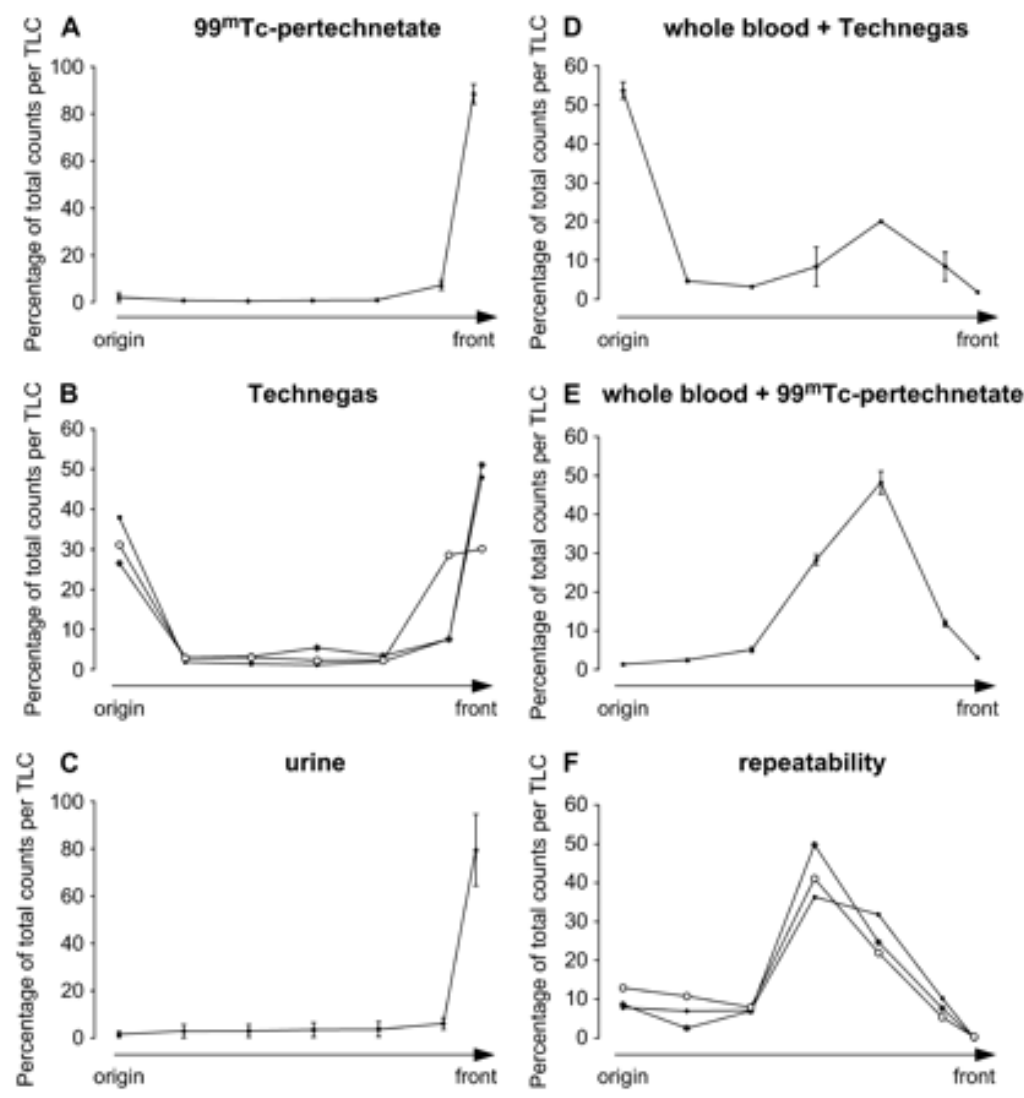

Figure 4. Thin-layer chromatography (TLC) controls: (A) Sodium ${ }^{99 m}$ Tcpertechnetate, showing a single peak at the solvent front; $(B)$ Technegas aerosol showing two peaks, one at the origin and the other at the solvent front, immediately (solid circles), 60 (asterisks), and 360 (open circles) minutes after aerosol collection; $(C)$ urine sample 60 min after inhalation showing a single peak at the solvent front; $(D)$ Technegas aerosol added to whole blood showing peaks at the origin and trailing the solvent front; $(E)$ sodium ${ }^{99 \mathrm{~m}} \mathrm{Tc}$-pertechnetate added to whole blood showing a single peak trailing the solvent front; $(F)$ replication of chromatography on a single blood sample. Values are mean \pm SEM.

Peaks were identified at the origin and trailing the solvent front when Technegas aerosol solution was added to whole blood (Figure 4D). The addition of sodium ${ }^{99 m}$ Tc-pertechnetate solution to whole blood produced a single peak trailing the solvent front, with no peak at the origin or front (Figure 4E). It is probable that 
this peak was due to ${ }^{99 m} \mathrm{Tc}$-pertechnetate held up by an interaction with one of more components in blood. Replication of chromatography on a single blood sample confirmed good repeatability of our technique (Figure 4F).

\section{Radionuclide Imaging}

The average decrease in lung radioactivity was $3.2 \pm 0.7 \%$ over the first hour, and $1.2 \pm 1.7 \%$ over the subsequent $5 \mathrm{~h}$ (Figure $5 \mathrm{~A}$ ). Radioactivity was present within the gastrointestinal tract and bladder, but no obvious uptake of ${ }^{99 \mathrm{~m}} \mathrm{Tc}$ by the liver or spleen was detected (Figure 5B). The level of radioactivity over the bladder region gradually increased with time, but did not accumulate in any other region (Figure 6).

A

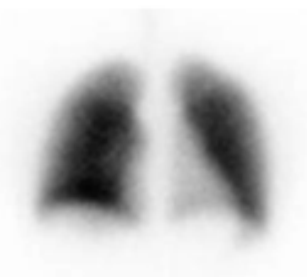

Baseline

$(100 \%)$

B

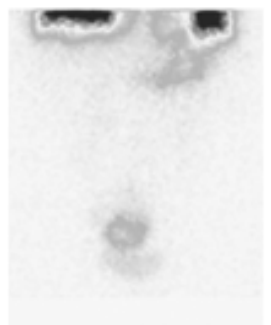

Antero-posterior

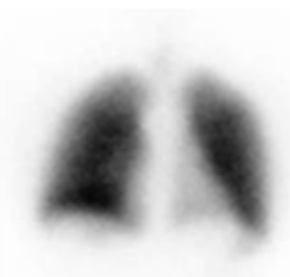

$60 \mathrm{~min}$

$(96.8 \pm 0.7 \%)$

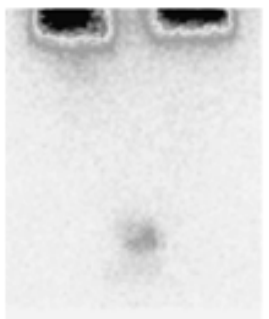

Postero-anterior

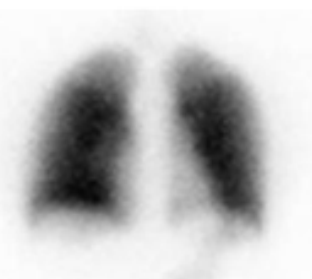

$360 \mathrm{~min}$

$(95.6 \pm 1.7 \%)$

Figure 5. (A) Typical anteroposterior lung images at 1, 60, and $360 \mathrm{~min}$ after inhalation of Technegas. Values of retention are mean \pm SEM. (B) Typical anteroposterior and posteroanterior abdominal images recorded at $360 \mathrm{~min}$ postinhalation of Technegas. 


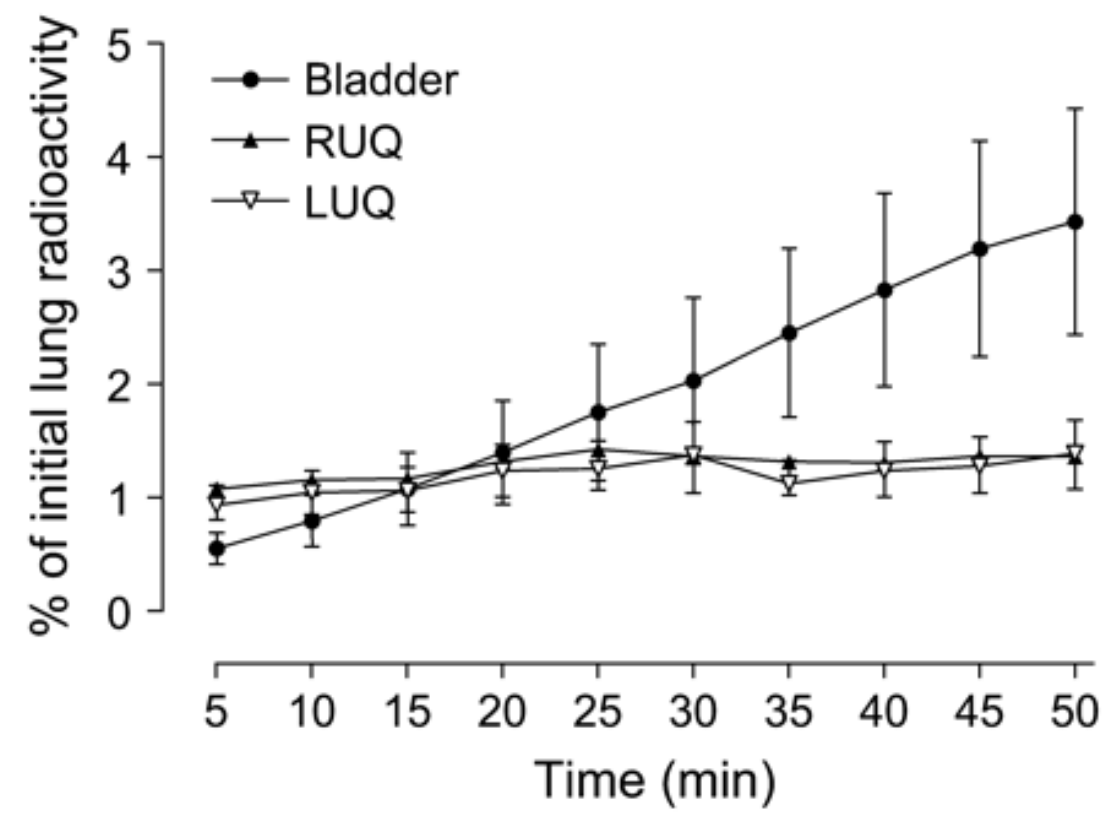

Figure 6. Time-activity curve over bladder and right and left upper quadrants (RUQ, LUQ) expressed as percentage of initial lung radioactivity. Values are mean \pm SEM

\section{DISCUSSION}

Air pollution has been consistently linked to adverse cardiovascular events (1-3); however, the mechanism responsible for this association is not well understood. Rapid translocation of inhaled nanoparticles into the systemic circulation with direct effects on the vasculature could potentially explain this association with cardiovascular risk. However, using ${ }^{99 \mathrm{~m}}$ Tc-radiolabeled carbon nanoparticles, we found no evidence to support this hypothesis.

After inhalation of Technegas, ${ }^{99 \mathrm{~m}} \mathrm{Tc}$ was immediately detected in blood, with levels increasing steadily over the first $60 \mathrm{~min}$. Thin-layer chromatography of whole blood identified a species that moved with the solvent, corresponding to unbound ${ }^{99 \mathrm{~m}} \mathrm{Tc}$-pertechnetate, but no evidence of significant particle-bound ${ }^{99 \mathrm{~m}} \mathrm{Tc}$ at the origin. The 7 camera images demonstrated high levels of ${ }^{99 \mathrm{~m}} \mathrm{Tc}$ retention $(96.8 \pm 0.7 \%$ at $1 \mathrm{~h})$ in the lungs. Losses were explained by the accumulation of ${ }^{99 \mathrm{~m}} \mathrm{Tc}$ in the bladder $(3.4 \pm 1.0 \%)$, which was confirmed as ${ }^{99 \mathrm{~m}} \mathrm{Tc}$-pertechnetate by chromatography of urine.

Nemmar and colleagues also detected ${ }^{99 \mathrm{~m}} \mathrm{Tc}$ in the bloodstream immediately after inhalation of Technegas (7). In contrast, the majority of ${ }^{99 \mathrm{~m}} \mathrm{Tc}$ remained at the origin of the chromatogram, suggesting the presence of circulating particle-bound ${ }^{99 \mathrm{~m}} \mathrm{Tc}$. In addition, substantial quantities of radioactivity were measured over the liver and other extrathoracic organs. The authors concluded that inhaled particlebound ${ }^{99 \mathrm{~m}}$ Tc rapidly translocates into the circulation, with particulate accumulating in the endoreticular system. Differences in aerosol composition, radionuclide imaging, and chromatography between our study and that of Nemmar and coworkers merit further discussion.

In the presence of even minute quantities of oxygen, the Technegas generator produces a mixed aerosol of ${ }^{99 \mathrm{~m}} \mathrm{Tc}$-labeled particles and soluble oxides of ${ }^{99 \mathrm{~m}} \mathrm{Tc}$ pertechnetate (Pertechnegas). Therefore, the presence of ${ }^{99 \mathrm{~m}} \mathrm{Tc}$ activity in the bloodstream or over extrathoracic organs does not in itself provide evidence of 
particle translocation. Pertechnegas is cleared from the lungs with a half-life of approximately $10 \mathrm{~min}(16)$, and has been used clinically to assess lung epithelial permeability (17). Pertechnegas and the free radiolabel ${ }^{99 \mathrm{~m}} \mathrm{Tc}$-pertechnetate behave similarly on chromatography (18), have identical clearance kinetics after inhalation (19), and identical distributions after intravenous infusion (18). The 6-h retention of approximately $95 \%$ of inhaled ${ }^{99 \mathrm{~m}} \mathrm{Tc}$ in our study is consistent with rates quoted by the manufacturer (11) and previous independent studies (12). The loss of $5 \%$ of ${ }^{99 \mathrm{~m}} \mathrm{Tc}$ over and above decay occurred within the first hour, with little further loss over the remaining $5 \mathrm{~h}$. The time course of this clearance pattern is highly suggestive of the diffusion of small quantities of Pertechnegas into the bloodstream.

Abdominal images demonstrate a clear increase in radioactivity in the bladder, which accounted for the loss of lung radioactivity after 60 min. Chromatography confirmed that the activity in the bladder was due to ${ }^{99 \mathrm{~m}} \mathrm{Tc}$-pertechnetate in the urine. The presence of soluble ${ }^{99 \mathrm{~m}} \mathrm{Tc}$ in the Technegas aerosol, the bloodstream, and in urine strongly suggests that a small amount of ${ }^{99 \mathrm{~m}} \mathrm{Tc}$ in the aerosol produced by our generator was in the form of ${ }^{99 \mathrm{~m}} \mathrm{Tc}$-pertechnetate or Pertechnegas, which diffused rapidly into the circulation and was eliminated via the renal tract.

In the study by Nemmar and colleagues, radioactivity over the bladder was present early and increased steadily with as much as $25 \%$ of total initial lung radioactivity present in the bladder at $45 \mathrm{~min}$ (7); chromatography confirmed that this activity was due to ${ }^{99 \mathrm{~m}} \mathrm{Tc}$-pertechnetate in urine. In addition, $10 \%$ of the initial lung radioactivity was present in the liver after $5 \mathrm{~min}$ and there were large quantities of radioactivity visible and unaccounted for in the thyroid, salivary glands, and stomach. From their data, we can infer that pulmonary retention of ${ }_{99 \mathrm{~m}} \mathrm{Tc}$ after $45 \mathrm{~min}$ would be no more than $65 \%$, although this value was not formally reported. This is in stark contrast to previous studies and the present study, and led to the highly plausible suggestion from one correspondent that large quantities of soluble ${ }^{99 \mathrm{~m}} \mathrm{Tc}$ had been produced by a generator contaminated with oxygen (11).

Given the very low pulmonary retention rates and the rapid accumulation of ${ }^{99 \mathrm{~m}} \mathrm{Tc}$-pertechnetate in urine, it is surprising that chromatography of the aerosol in Nemmar and coworkers' study suggests it consisted only of $99 \mathrm{~m}$ Tc-labeled particles with no ${ }^{99 m}$ Tc-pertechnetate or Pertechnegas. Despite using the same generator and purity of argon, this was not the case in our study or in a previous study (20). Scalzetti and Gagne used thin-layer chromatography to investigate the effect of increasing the ratio of oxygen to argon in the generator on the transition of Technegas to Pertechnegas (20). When using the recommended highly purified argon ( $99.998 \%$ purity), as in our study, they still found approximately $20 \%$ of the ${ }^{99 \mathrm{~m}} \mathrm{Tc}$ migrated with the solvent front. In oxygen concentrations of $0.1 \%$ or more, an abrupt transition from Technegas to Pertechnegas occurred, with more than $50 \%$ of the ${ }^{99 \mathrm{~m}} \mathrm{Tc}$ moving with the solvent front (20).

Approximately $5 \%$ of inhaled ${ }^{99 \mathrm{~m}} \mathrm{Tc}$ in our study was in the form of unbound ${ }^{99 \mathrm{~m}} \mathrm{Tc}-$ pertechnetate and diffused rapidly into the circulation before elimination via the renal tract. Thin-layer chromatography identified this small quantity of ${ }^{99 \mathrm{~m}} \mathrm{Tc}-$ pertechentate in the bloodstream as a consistent and reproducible peak trailing the solvent front. In the study by Nemmar and colleagues, $25 \%$ of ${ }^{99 m}$ Tc was filtered by the kidneys within the first 45 min, yet chromatography did not reliably identify unbound ${ }^{99 \mathrm{~m}} \mathrm{Tc}$-pertechnetate in the bloodstream; the largest peak occurred at the origin and was ascribed to particle-bound ${ }^{99 \mathrm{~m}} \mathrm{Tc}$. To explain the lack of consistency between chromatograms of the aerosol, blood, and urine, 
Nemmar and colleagues suggested that soluble oxides of ${ }^{99 \mathrm{~m}} \mathrm{Tc}$-pertechnetate may be being produced in vivo (7). Although plausible, there was no evidence of in vitro oxidation in either Nemmar and coworkers' or our own control studies.

It is possible that differences in chromatography technique could explain this disparity. Nemmar and colleagues dried the blood sample at the origin of the plate before running the chromatogram (A. Nemmar, personal communication), whereas we placed it immediately into the mobile phase. It is possible that a period of drying would favor ${ }^{99 \mathrm{~m}} \mathrm{Tc}$ retention at the origin. Interestingly, in our study, there was a small but reproducible peak of activity at the origin in blood sampled $6 \mathrm{~h}$ after inhalation. This may reflect particle-bound activity due to translocation via a different mechanism involving a slower active transfer of particles from the lung into the circulation. Alternatively, the activity may be intracellular due to phagocytosis of particulate in the lung alveolar space or interstitium by cells of the monocyte/macrophage lineage, which then enter the circulation. Further studies are required to determine the significance of this finding. Thin-layer chromatography is an indirect method of particle detection, and ideally, a more direct strategy could be used to track particles in the bloodstream. Techniques such as electron microscopy would be limited by the small concentration of particles, difficulty resolving structures in the nanoparticulate range, and the low electron density of carbon.

In the study by Nemmar and colleagues (7), $10 \%$ of the initial lung radioactivity was present in the liver after $5 \mathrm{~min}$, which the authors suggest is due to the accumulation of circulating particles in the Kupffer cells. If most of the circulating ${ }^{99 \mathrm{~m}} \mathrm{Tc}$ were particle bound and cleared in this way, then radioactivity should increase over time in the liver. However, it did not, but rather increased steadily in the bladder. It is possible that the large amount of activity measured over the liver was not associated with the liver and simply reflected scatter from the lung. An alternative explanation could relate to the vascularity of this organ. If there is a large quantity of circulating unbound ${ }^{99 \mathrm{~m}} \mathrm{Tc}$, either as Pertechnegas from a generator contaminated with oxygen or from oxidation in vivo, then radioactivity over highly vascular organs might well be high. Furthermore, it would remain static, as hepatic blood flow is unlikely to change during the course of the study, or even decrease, because ${ }^{99 \mathrm{~m}} \mathrm{Tc}$-pertechnetate is filtered by the kidneys.

In our study, the only discernable pattern of radioactivity across the abdomen, other than the bladder, was suggestive of gastrointestinal uptake, which is likely to be due to either mucociliary clearance of particles from the bronchial tree or swallowing of particles that had deposited in the mouth. The small quantities of radioactivity detected in the left and right upper quadrants likely reflect scatter from the lung or overlap of the lung and liver parenchyma. This absence of appreciable radioactivity in the liver or spleen is consistent with previous animal (21) and human studies (12). There were small amounts of activity in the thyroid and stomach at 60 and 360 min after inhalation, both glandular organs in which ${ }^{99 \mathrm{~m}} \mathrm{Tc}$-pertechnetate is known to localize.

The ability of nanoparticles to cross the lung-blood barrier is likely to be influenced by particle size. Differences in size of the primary particle and in the degree of particle aggregation could potentially explain the differences between study results. In our aerosol, the majority of particles were singlet and less than $10 \mathrm{~nm}$ in diameter, but these rapidly formed aggregates of approximately $100 \mathrm{~nm}$ in diameter in the inhaled aerosol. Nemmar and colleagues identified 5-nm particles (7), but the average particle size and the size distribution of aggregated particles in the inhaled aerosol were not reported. During our study, a standard protocol for generating and administering Technegas was followed, making it 
unlikely that particles would aggregate to a greater or lesser extent than in previous studies.

The escape of nanoparticulate from the lung into the bloodstream has been advanced as a mechanism for the adverse cardiovascular effects of air pollution, although "engineered" nanoparticles in the nanotechnology industry could pose the same risks (22). The fact that Technegas nanoparticles do not translocate directly into the blood in this study does not necessarily mean that other nanoparticles behave similarly, nor does it rule out an interaction between inhaled particulate and the vasculature. Environmental combustion-derived nanoparticulate, as a carrier of soluble organic compounds from unburned hydrocarbon fuels (23) and oxidized transition metals (24), may well exert an important influence on the cardiovascular system.

In conclusion, our results suggest that small quantities of soluble ${ }^{99 m} \mathrm{Tc}$ species, not ${ }^{99 \mathrm{~m}} \mathrm{Tc}$-radiolabeled nanoparticles, are responsible for the increase in radioactivity found in the bloodstream after Technegas inhalation. Robust chromatography and clear radionuclear imaging provide support for this statement. The low pulmonary retention rates of ${ }^{99 \mathrm{~m}} \mathrm{Tc}$ and whole body images reported in Nemmar and colleagues are suggestive of a high degree of Pertechnegas contamination (7). However, thin-layer chromatographic analysis of their aerosol, blood, and urine are not entirely consistent with this, and in light of our findings are difficult to explain. A better knowledge of the toxicokinetics of nanoparticulate is required before we can make general conclusions about the behavior of other inhaled environmental and engineered nanoparticles.

\section{Acknowledgments}

The authors thank Paul Fokkens of the National Institute of Public Health and the Environment, the Netherlands, and the Wellcome Trust Clinical Research Facility, Edinburgh, for their assistance with the studies.

\section{FOOTNOTES}

Supported by the British Heart Foundation project grant 03/017/15071.

Originally Published in Press as DOI: $10.1164 / \mathrm{rccm} .200506-8650 \mathrm{C}$ on December 9, 2005

Conflict of Interest Statement: None of the authors have a financial relationship with a commercial entity that has an interest in the subject of this manuscript. 


\section{REFERENCES}

1. Pope CA III, Burnett RT, Thurston GD, Thun MJ, Calle EE, Krewski D, Godleski Jj. Cardiovascular mortality and long-term exposure to particulate air pollution: epidemiological evidence of general pathophysiological pathways of disease. Circulation 2004;109:71-77.

2. Dockery DW, Pope CA, Xu XP, Spengler JD, Ware JH, Fay ME, Ferris BG, Speizer FE. An association between air-pollution and mortality in 6 United-States cities. N Engl J Med 1993;329:1753-1759.

3. Samet JM, Dominici F, Curriero FC, Coursac I, Zeger SL. Fine particulate air pollution and mortality in 20 US cities, 1987-1994. N Engl J Med 2000;343:1742-1749.

4. Donaldson K, Stone V, Clouter A, Renwick L, MacNee W. Ultrafine particles. Occup Environ Med 2001;58:211-216.

5. Brook RD, Franklin B, Cascio W, Hong Y, Howard G, Lipsett M, Luepker R, Mittleman M, Samet J, Smith SC Jr, et al. Air pollution and cardiovascular disease: a statement for healthcare professionals from the expert panel on Population and Prevention Science of the American Heart Association. Circulation 2004;109:2655-2671.

6. Seaton A, MacNee W, Donaldson K, Godden D. Particulate air-pollution and acute healtheffects. Lancet 1995;345:176-178.

7. Nemmar A, Hoet PH, Vanquickenborne B, Dinsdale D, Thomeer M, Hoylaerts MF, Vanbilloen $\mathrm{H}$, Mortelmans L, Nemery B. Passage of inhaled particles into the blood circulation in humans. Circulation 2002;105:411-414.

8. Lemb M, Oei TH, Eifert $H$, Gunther B. Technegas: a study of particle structure, size and distribution. Eur J Nucl Med 1993;20:576-579.

9. Oberdorster G, Sharp Z, Atudorei V, Elder A, Gelein R, Lunts A, Kreyling W, Cox C. Extrapulmonary translocation of ultrafine carbon particles following whole-body inhalation exposure of rats. J Toxicol Environ Health A 2002;65:1531-1543.

10. Nemmar A, Vanbilloen $H$, Hoylaerts MF, Hoet PH, Verbruggen A, Nemery B. Passage of intratracheally instilled ultrafine particles from the lung into the systemic circulation in hamster. Am J Respir Crit Care Med 2001;164:1665-1668.

11. Burch WM. Passage of inhaled particles into the blood circulation in humans. Circulation 2002;106: e141-e142.

12. Brown JS, Zeman $\mathrm{KL}$, Bennett WD. Ultrafine particle deposition and clearance in the healthy and obstructed lung. Am J Respir Crit Care Med 2002;166:1240-1247.

13. Mills NL, Amin N, Robinson SD, Millar AM, Boon NA, MacNee W, Donaldson K, Newby DE. Inhalation of $99^{\mathrm{m}} \mathrm{Technetium-labeled}$ carbon particles and translocation to the human circulation . Eur Respir J 2004;24:605s.

14. Cook G, Clarke SE. An evaluation of Technegas as a ventilation agent compared with krypton-81m in the scintigraphic diagnosis of pulmonary embolism. Eur J Nucl Med 1992;19:770-774.

15. Tetley Manufacturing Ltd. Technegas generator user manuel. Sydney, Australia: Tetley Manufacturing; 1986.

16. Mackey DW, Jackson P, Baker RJ, Dasaklis C, Fisher KJ, Magee M, Bush V, Burch WM. Van der WH, Willett GD. Physical properties and use of pertechnegas as a ventilation agent. J Nucl Med 1997;38:163-167.

17. Monaghan P, Provan I, Murray C, Mackey DW. Van der WH, Walker BM, Jones PD. An improved radionuclide technique for the detection of altered pulmonary permeability. J Nucl Med 1991;32:1945-1949. 
American Journal of Respiratory and Critical Care Medicine Vol 173. pp. 426-431, (2006)

18. Tominaga S, Shimada T, Kawakami K, Yoshizawa Y. Physicochemical characterization and lung clearance of Pertechnegas [in Japanese]. Kaku Igaku 1995;32:563-567.

19. Isawa T, Teshima T, Anazawa Y, Miki M, Mahmud AM. Inhalation of pertechnegas: similar clearance from the lungs to that of inhaled pertechnetate aerosol. Nucl Med Commun $1995 ; 16: 741-746$.

20. Scalzetti EM, Gagne GM. The transition from technegas to pertechnegas. J Nucl Med $1995 ; 36: 267-269$.

21. Kreyling WG, Semmler M, Erbe F, Mayer P, Takenaka S, Schulz H, Oberdorster G, Ziesenis A. Translocation of ultrafine insoluble iridium particles from lung epithelium to extrapulmonary organs is size dependent but very low. J Toxicol Environ Health A 2002;65:1513-1530.

22. Donaldson K, Stone V, Tran CL, Kreyling W, Borm PJA. Nanotoxicology. Occup Environ Med 2004;61:727-728.

23. Levsen K. The analysis of diesel particulate. Frenzius Z Anal Chem 2002;331:467-478.

24. Sydbom A, Blomberg A, Parnia S, Stenfors N, Sandstrom T, Dahlen SE. Health effects of diesel exhaust emissions. Eur Respir J 2001;17:733-746. 